Research Article

\title{
Mechanical Characteristics and Failure Mechanism of Siltstone with Different Joint Thickness
}

\author{
Huigui Li $\mathbb{D}^{1},{ }^{1}$ Zhengkai Yang $\mathbb{D}^{2,3}$ and Huamin $\mathrm{Li} \mathbb{D}^{4}$ \\ ${ }^{1}$ College of Mining Engineering, Guizhou University of Engineering Science, Bijie, Guizhou 551700, China \\ ${ }^{2}$ School of Energy and Mining Engineering, China University of Mining \& Technology, Beijing 100083, China \\ ${ }^{3}$ China Coal Research Institute, Beijing 100013, China \\ ${ }^{4}$ School of Energy Science and Engineering, Henan Polytechnic University, Jiaozuo, Henan 454000, China \\ Correspondence should be addressed to Huigui Li; lihuigui1221@163.com
}

Received 3 December 2019; Revised 4 October 2020; Accepted 10 October 2020; Published 24 October 2020

Academic Editor: Payam Shafigh

Copyright (C 2020 Huigui Li et al. This is an open access article distributed under the Creative Commons Attribution License, which permits unrestricted use, distribution, and reproduction in any medium, provided the original work is properly cited.

\begin{abstract}
The mechanics of rock mass is significantly affected by joints, but many existing studies of jointed rocks make simplifications that do not consider the joint thickness. To further study the influence of joint thickness on rock mechanics (mechanical properties, failure mechanism, damage model, etc.), we fabricated jointed siltstone specimens with different joint thickness $(5,10,15$, and $20 \mathrm{~mm}$ ) and the specimens were subjected to uniaxial compression tests. The effects of joint thickness on the uniaxial compression strength (UCS), the strain at UCS, the elastic modulus, and the stress-strain curves were thus analyzed. For the stress-strain curve, with rising joint thickness, the upper concave in the initial compression stage intensified, the slope of the stress-strain in the elastic stage decreased, and the sudden stress drop after peak strength became more obvious. Both the peak compression strength and the elastic modulus gradually decreased with rising joint thickness, but a positive correlation was found between the strain at UCS and the joint thickness.
\end{abstract}

\section{Introduction}

Shendong coalfield is the most representative of the northwest region of coal mining technology development in China. The coal seams are buried relatively shallow and their overlying bedrock strata are thin. There is a large count of different thickness joints filled between the rock layers due to the special historical sedimentary environment, as shown in Figure 1. Those joints can affect the rock mechanics properties, failure mode, and wave velocity obviously (Du et al. [1], Li et al. [2], Zhao et al. [3], and Ma et al. [4]).

In recent years, the physical and mechanical properties of joint rocks have gradually attracted the attention of researchers (Chen et al. [5]; Lian et al. [6]; Chen et al. [7]; Zhang et al. [8]). The study of mechanical characteristics of jointed rock mainly includes laboratory testing, numerical simulation, and theoretical analysis. Li et al. [9] carried out a series of mechanical uniaxial and triaxial compression tests on specimens of rock salt, interlayer, and composite rock salt, and they found that the inclined interlayer affected the deformation and fracture properties of rock salt. The influence of natural weak interbeds with different dip angles $\left(0^{\circ}, 30^{\circ}, 45^{\circ}, 60^{\circ}\right.$, and $\left.90^{\circ}\right)$ on the mechanical characteristics of marble was studied by Song et al. [10]. They found that weak intercalation has a weakening effect on its mechanical properties. Ke et al. [11] studied the relationship between the dip angle of perforated joints and the postpeak stress-strain curves, failure modes, and postpeak residual strength. The influence of the size of the specimen and the dip angle of the joint on the uniaxial compressive strength of single jointed rock was studied by Wasantha et al. [12]; they believed that when the dip angle is 63 degrees, it has the greatest impact on the UCS of the rock. Wang et al. [13] had conducted a series of true triaxial loading and unloading experiments by using concrete specimens containing inclined cracks with inclinations of $15^{\circ}, 30^{\circ}, 45^{\circ}, 60^{\circ}$, and $75^{\circ}$ to analyze the influence of the joint dip on the crack propagation. The prepeak cyclic numerical direct shear test of rock joints considering 


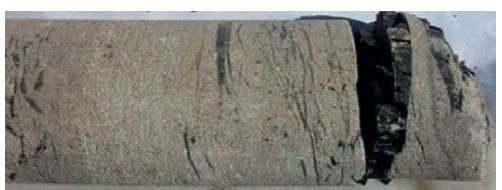

\begin{tabular}{lc} 
Sampling site & Buertai mine \\
\hline Sampling depth & $291.92 \mathrm{~m}$ \\
Joint thickness & $1.5 \mathrm{~cm}$ \\
Joint lithology & Coal \\
\hline
\end{tabular}

(a)

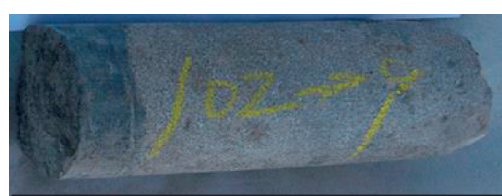

Sampling site Buertai mine

Sampling depth

Joint thickness

Joint lithology
$295.72 \mathrm{~m}$

$5 \mathrm{~cm}$

Mudstone

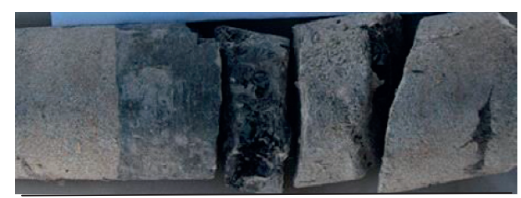

\begin{tabular}{lc} 
Sampling site & Buertai mine \\
\hline Sampling depth & $321.53 \mathrm{~m}$ \\
Joint thickness & $7 \mathrm{~cm}$ \\
Joint lithology & Coal
\end{tabular}

(c)

FIgURE 1: Example siltstone planes with different joint thickness.

second-order asperity was implemented using a two-dimensional granular now (PFC2D) program by Liu et al. [14]. The mechanical properties of the natural jointed limestone were studied under uniaxial and triaxial compression tests by $\mathrm{Su}$ et al. [15], and they found that there were three destruction modes of the limestone with natural joints. The mechanical characteristics of 4 kinds of rock mass with different inclination angles were studied by laboratory experiment and numerical simulation, which indicated that the dip angle has an obvious influence on the failure strength of the combined coal and rock mass by Guo et al. [16].

A large number of scholars studied the mechanical behavior of jointed rock mass by numerical simulation. Vergara et al. [17] used UDEC to study the strength and failure modes of rock containing nonpersistent joints; they found that the joint spacing and angle have a marked influence on the uniaxial strength of the rock. Bahaaddin et al. [18] employed code $\mathrm{PFC}^{3 \mathrm{D}}$ to analyze the effects of joint geometrical parameters, including joint orientation angle, spacing, persistency degree, step angle, and aperture on UCS and the deformation modulus, in which they found that the joint geometrical parameters have an important influence on UCS and the deformation modulus, while the joint orientation angle had the greatest effects on the mechanical characteristics of rock mass. Yu et al. [19] created a numerical model based on the computerized tomography (CT) scanning microstructure photo of a jointed sandstone specimen and investigated the fracture evolution mechanism of jointed rocks by using the three-dimensional rock failure process analysis software RFPA ${ }^{3 \mathrm{D}}$. The influence of joint thickness and loading rate on the dynamic compression strength of rock was studied under a separate Hopkinson test with a similar material model, which indicated that the dynamic compression strength of the jointed rock gradually decreased with the increase of the thickness of the joint by Yang et al. [20]. Yu et al. [21] used $\mathrm{PFC}^{2 \mathrm{D}}$ to establish a rock joint shear test model and studied the normal stress, shear mechanical behavior, and microcrack evolution. Wang et al. [22] used $\mathrm{PFC}^{2 \mathrm{D}}$ to establish the particle flow model of different dip layered rock, and the influence of the joint dip on the strength and failure mode of rock was analyzed, which found that the uniaxial compressive strength of the layered rock mass decreased gradually with the gradual increase of the joint inclination and then gradually increases, showing a distribution of $U$ shape.

The research studies above studied the influence of joint dip angle, joint size, and loading and unloading mode on the mechanical properties, failure mode, fracture evolution law, and stress-strain curve of rock; however, those research studies considered the joint as a simple single interface. In fact, the joint commonly has a certain thickness in rock strata. The existence of the joint will have a certain effect on the mechanical characteristics and failure mechanism of rock. Therefore, it has theoretical and practical significance to study the influence of the joint thickness on the mechanical characteristics of rock and its failure mechanism. In this work, four kinds of siltstone with different joint thickness were processed, and a series of uniaxial compression tests was carried out on a RMT-150C mechanical test machine. The influence of the joint thickness on the mechanical parameters was analyzed, and the failure mechanism of siltstone with different joint thickness was discussed.

\section{Sample Processing and Test Scheme}

2.1. Preparation of Test Sample. Columnar siltstone samples were prepared as shown in Figure 2 with a coal joint of 5, 10, 15 , and $20 \mathrm{~mm}$ thickness and a joint angle of $0^{\circ}$ (i.e., the joint is parallel to the sample's end surface). Siltstone columns of $50 \mathrm{~mm}$ height were cut from the siltstone rocks, and the ends were polished by a grindstone machine. Meanwhile, a cutting machine was used to cut the processed cylinder coal into slices of 5, 10, 15, and $20 \mathrm{~mm}$ thickness, and the ends were also polished by a grindstone machine. The coal slice and the rock parts were then joined with $\mathrm{AB}$ glue, and the resulting columnar specimen was placed on a grindstone machine to trim equally from both ends to give a total height of $100 \mathrm{~mm}$. The thickness of $A B$ adhesive is very thin, which has no effect on the strength of the sample. The error of the nonparallel degree of the two ends was $<0.05 \%$. Figure 3 shows the prepared specimens with different joint thickness.

2.2. Test Scheme. The fabricated samples with joint thickness of 5, 10, 15, and $20 \mathrm{~mm}$ were denoted as DF5, DF10, DF15, and DF20. Two other samples of a columnar specimen $(100 \mathrm{~mm})$ consisting of intact siltstone or plain coal, referred 


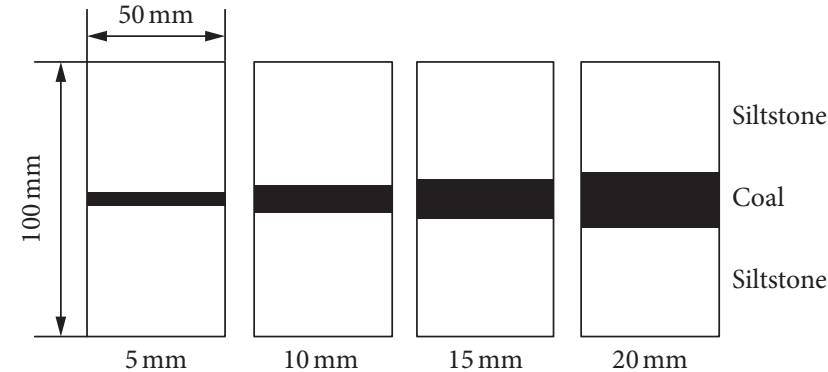

Figure 2: Illustration of samples with coal joints of different thickness.

to as DFS and DFC, respectively, were also tested. The displacement control method was used in the mechanical test, and the loading rate was $0.002 \mathrm{~mm} / \mathrm{s}$. Table 1 lists the detailed results. Three specimens were tested for each group.

\section{Influence of Joint Thickness on the Mechanical Characteristics of Siltstone}

3.1. Influence of Joint Thickness on the Stress-Strain Curve. Figure 4 shows the stress-strain curves of intact siltstone, plain coal, and jointed siltstone with a coal layer thickness of $5,10,15$, and $20 \mathrm{~mm}$. The stress-strain curves of most specimens are clearly divided into four stages: the initial compaction stage, the online elastic phase, the plastic deformation and failure stage, and the postpeak stress stage. In both the initial compassion stage and the online elastic phase, the slope of the curve decreased gradually with rising joint thickness. That is, the joint thickness has a direct influence on the elastic modulus of the siltstone. In the plastic deformation and failure stage, the slope also gradually decreased with rising joint thickness, and the structure and the curve had a step up phenomenon. With rising joint thickness, the rate of performance of the release projectile has a decreasing trend. In the postpeak period, the bearing capacity of the siltstone reduced to 0 after peak stress. As the joint thickness increased, the trend gradually changed. After the peak stress, the transition from brittle failure to plastic failure is clearly visible on the curve. Thus, the joint thickness has a notable influence on the failure mode of the jointed siltstone.

\subsection{Influence of Joint Thickness on Mechanical Parameters.} Table 1 lists the mechanical parameters of the tested specimens under uniaxial compression, where $\sigma_{c}$ is the uniaxial compression strength (UCS), $\varepsilon_{c}$ is the strain at UCS, $E$ is the elastic modulus, and $v$ is Poisson's ratio. The average UCS was $80.78 \mathrm{MPa}$ for DFS, $22.97 \mathrm{MPa}$ for DFC, and 43.70 , $40.60,34.08$, and $30.81 \mathrm{MPa}$ for DF5, DF10, DF15, and DF20, respectively. That is, for DF5, DF10, DF15, and DF20, UCS dropped by $45.9 \%, 49.7 \%, 57.8 \%$, and $62.6 \%$ from that of DFS but increased by $90.2 \%, 76.8 \%, 48.4 \%$, and $34.1 \%$ from that of DFC, respectively. The linear fitting equation between the compression strength and the joint thickness gives a correlation coefficient of 0.98 :

$$
\sigma_{c}=48.34-0.89 d,
$$

where $\sigma_{c}$ is the peak compressive strength (MPa) and $d$ is the joint thickness $(\mathrm{mm})$.

The strain at UCS $\left(\varepsilon_{c}\right)$ is positively correlated with the joint thickness, giving a linear fitting equation as follows:

$$
\varepsilon_{c}=6.53+0.07 d,
$$

where $\varepsilon_{c}$ is the peak strain and $d$ is the joint thickness $(\mathrm{mm})$. An aberration in the peak strain was observed when the joint thickness is $15 \mathrm{~mm}$ (Figure 5(b)), and the standard deviation of the peak strain is also the largest for DF15. In other words, the strain at UCS must be discrete. The linear fitting between $\varepsilon_{c}$ and joint thickness has a lower correlation coefficient $\left(R^{2}=0.70\right)$ due to the discretization.

Figure 5(c) illustrates the relation between the joint thickness and the elastic modulus. The average elastic modulus was $15.56 \mathrm{GPa}$ for DFS and decreased by $53.4 \%$, $59.8 \%, 69.2 \%$, and $69.7 \%$ to $7.25,6.25,4.80$, and $4.72 \mathrm{GPa}$ for DF5, DF10, DF15, and DF20, respectively. The elastic modulus approached a plateau with rising joint thickness. Exponential fitting between the elastic modulus and the joint thickness gives, the correlation coefficient was 0.88 :

$$
E=4.66+8.73 \times 0.8^{d},
$$

where $E$ is the modulus of elasticity $(\mathrm{GPa})$ and $d$ is the joint thickness (mm).

\section{Influence of Joint Thickness on the Failure Characteristics of Siltstone}

Figure 6 shows the failure of different specimens, the pictures of which all exhibited a broken zone. Tensile shear failure was dominant for DFS. For DF5, there was no obvious shear failure surface in the siltstone, and the failure of the coal body was not very serious and only had a few broken areas. For DF10, the failure weakened in the siltstone but intensified in coal, and some horizontal cracks and fractured zones could be noted in the coal. For DF15, the coal sample experienced stronger crushing and exhibited a larger broken area. For DF20, the coal experienced serious damage and there were no cracks crossing the coal. The cracks around the interface are mainly I-shaped, but with the change of joint thickness, the crack length changes. Therefore, as the joint thickness increases, the compression energy is transferred from the rock to the coal, and the impact strength will be weakened. The joint thickness thus has a strong influence on the damage model of jointed siltstone, and with rising joint thickness, the crack growth weakens and the area of the fracture zone declines in the siltstone part.

\section{Influence of Joint Thickness on the Failure Mechanism of Siltstone}

In the 1970s, Lemaitre proposed the strain equivalent hypothesis to indirectly measure material damage (Lemaitre [23]). The formula is as follows: 


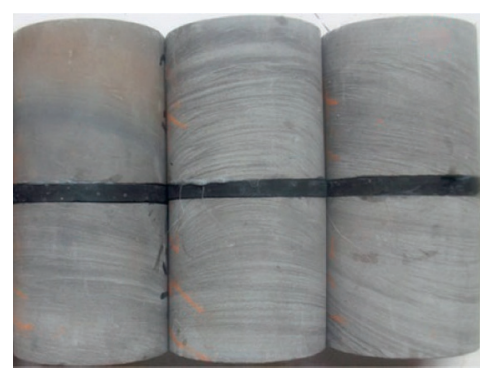

(a)

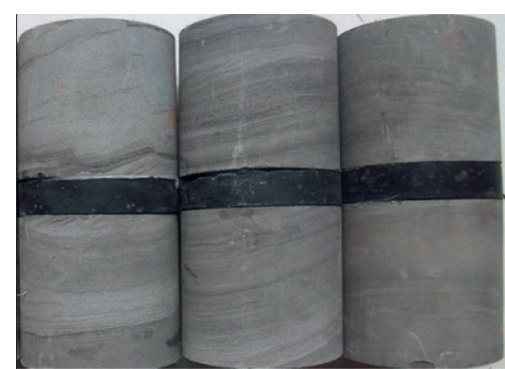

(b)

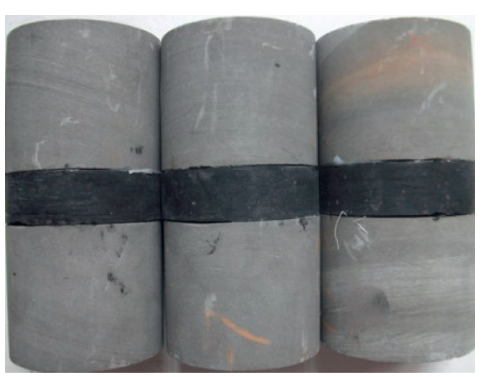

(c)

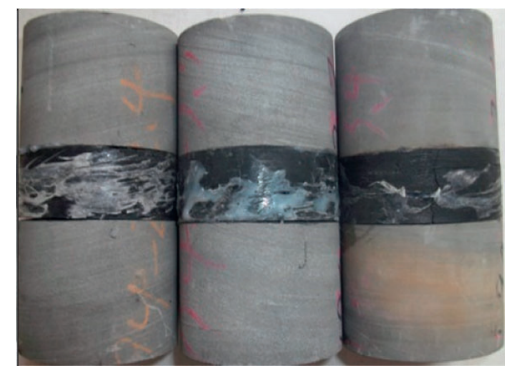

(d)

FIGURE 3: Fabricated specimens with joint thickness of (a) $5 \mathrm{~mm}$, (b) $10 \mathrm{~mm}$, (c) $15 \mathrm{~mm}$, and (d) $20 \mathrm{~mm}$.

TABLE 1: Mechanical parameters of specimens under uniaxial compression.

\begin{tabular}{|c|c|c|c|c|c|c|c|}
\hline Lithology & Sample & $H(\mathrm{~mm})$ & $D(\mathrm{~mm})$ & $\sigma_{c}(\mathrm{MPa})$ & $\varepsilon_{c}\left(10^{-3}\right)$ & $E(\mathrm{GPa})$ & $v$ \\
\hline \multirow{3}{*}{ Siltstone } & DFS-1 & 99.60 & 49.92 & 87.32 & 5.58 & 18.19 & 0.22 \\
\hline & DFS-2 & 99.42 & 49.90 & 79.11 & 5.70 & 15.52 & 0.26 \\
\hline & DFS-3 & 99.24 & 49.98 & 75.90 & 6.82 & 12.98 & 0.22 \\
\hline \multirow{12}{*}{ Jointed siltstone } & DF5-1 & 100.36 & 49.90 & 44.19 & 7.60 & 7.04 & 0.29 \\
\hline & DF5-2 & 99.60 & 49.80 & 44.18 & 6.98 & 7.05 & 0.30 \\
\hline & DF5-3 & 98.96 & 49.72 & 42.74 & 6.22 & 7.67 & 0.24 \\
\hline & DF10-1 & 99.76 & 49.72 & 38.90 & 7.13 & 6.74 & 0.24 \\
\hline & DF10-2 & 99.86 & 49.80 & 40.91 & 8.02 & 5.97 & 0.18 \\
\hline & DF10-3 & 100.10 & 49.88 & 41.99 & 7.75 & 6.05 & 0.31 \\
\hline & DF15-1 & 100.02 & 50.02 & 29.85 & 10.75 & 3.78 & 0.24 \\
\hline & DF15-2 & 99.10 & 49.72 & 38.02 & 8.22 & 5.58 & 0.31 \\
\hline & DF15-3 & 98.96 & 49.96 & 34.38 & 7.47 & 5.05 & 0.26 \\
\hline & DF20-1 & 100.10 & 49.86 & 32.21 & 8.02 & 4.90 & 0.31 \\
\hline & DF20-2 & 96.80 & 49.62 & 29.27 & 7.60 & 4.59 & 0.36 \\
\hline & DF20-3 & 99.80 & 49.90 & 30.95 & 8.09 & 4.67 & 0.31 \\
\hline \multirow{3}{*}{ Coal } & DFC-1 & 100.40 & 49.60 & 21.05 & 14.26 & 1.61 & 0.19 \\
\hline & DFC-2 & 99.20 & 50.10 & 24.24 & 15.97 & 1.77 & 0.21 \\
\hline & DFC-3 & 100.40 & 49.90 & 23.61 & 17.32 & 1.39 & 0.18 \\
\hline
\end{tabular}

$$
\varepsilon=\frac{\widetilde{\sigma}}{E}=\frac{\sigma}{E(1-D)}=\frac{\sigma}{\widetilde{E}}
$$

where $\sigma$ is the axial stress $(\mathrm{MPa}), \tilde{\sigma}$ is the axial effective stress $(\mathrm{MPa}), E$ is the elastic modulus of the material $(\mathrm{GPa}), \widetilde{E}$ is the elastic modulus of the material after damage $(\mathrm{GPa})$, and $\varepsilon$ is the axial strain.

A damage model can be formulated from equation (4) for uniaxial compression as

$$
\sigma=E \varepsilon(1-D)
$$

Assuming that the strength of the rock microelement or the failure of the microelement conforms to the Weibull distribution, the probability density function of the rock can be expressed as follows (Wu et al. [24], Sun et al. [25], and Liu et al. [26]):

$$
P(F)=\frac{m}{F_{0}} \cdot\left(\frac{F}{F_{0}}\right)^{m-1} \cdot \exp \left[-\left(\frac{F}{F_{0}}\right)^{m}\right],
$$

where $F$ is the distribution variable of the Weibull distribution, $F_{0}$ is the parameter of the Weibull distribution, and $m$ is the parameter of the Weibull distribution. 


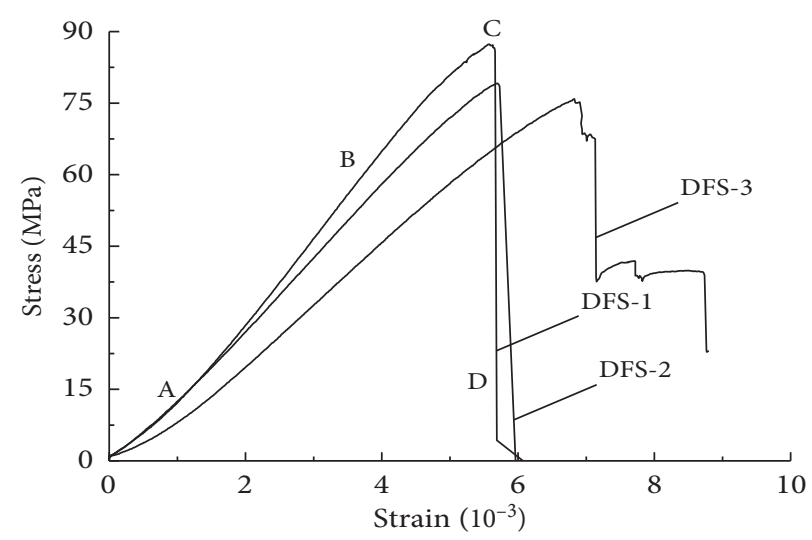

(a)

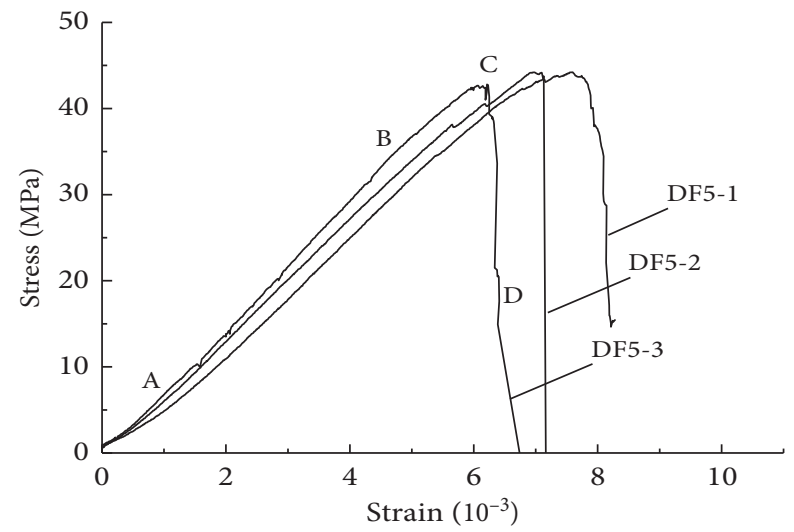

(c)

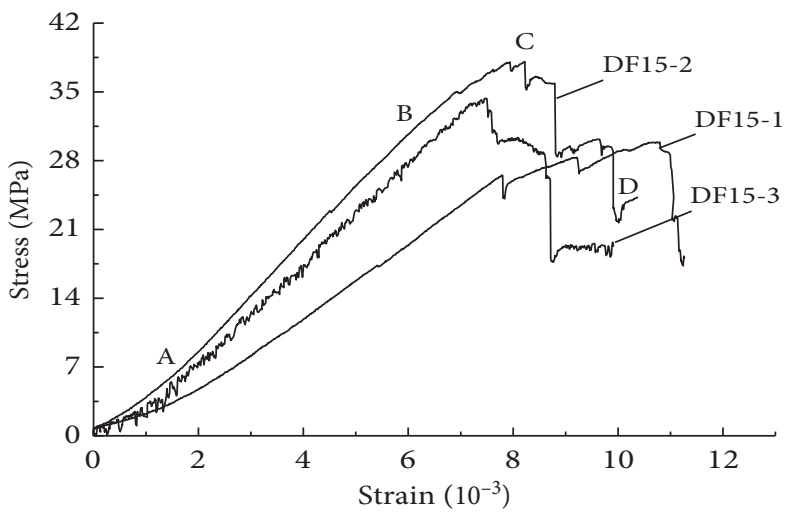

(e)

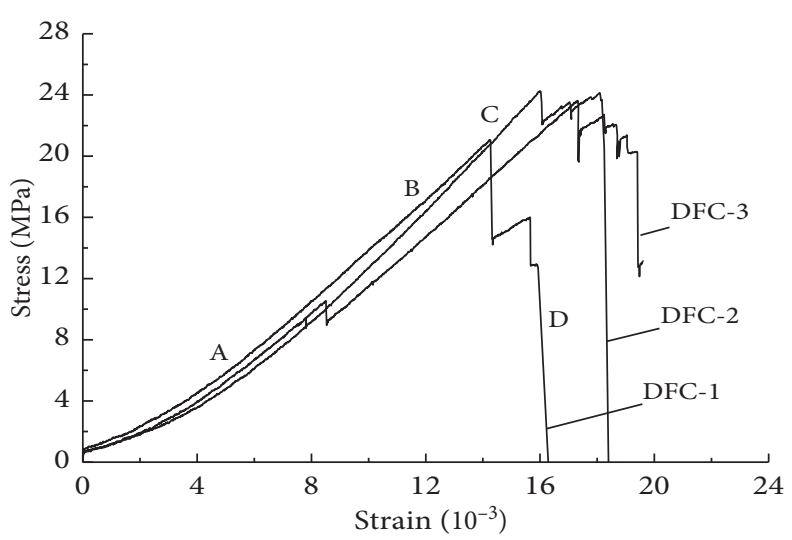

(b)

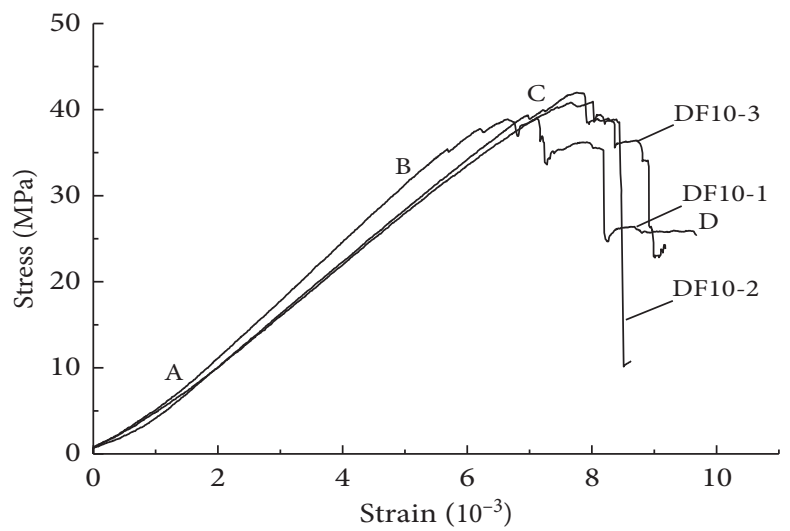

(d)

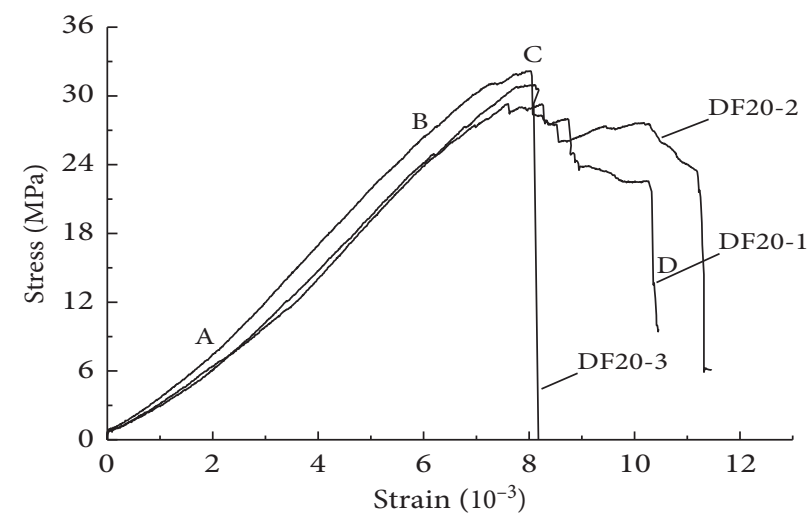

(f)

Figure 4: Stress-strain curves of (a) siltstone, (b) coal, or jointed siltstone with a coal layer of (c) $5 \mathrm{~mm}$, (d) $10 \mathrm{~mm}$, (e) $15 \mathrm{~mm}$, and (f) $20 \mathrm{~mm}$ thickness under uniaxial compression.

With strain as the damage variable, the damage factor $D$ can be calculated from the following equation:

$$
D=\int_{0}^{\varepsilon} \frac{m}{F_{0}} \cdot\left(\frac{\varepsilon}{F_{0}}\right)^{m-1} \exp \left[-\left(\frac{\varepsilon}{F_{0}}\right)^{m}\right] d \varepsilon=1-\exp \left[-\left(\frac{\varepsilon}{F_{0}}\right)^{m}\right] .
$$

By taking equations (7) into (5), we have

$$
\sigma=E \cdot \varepsilon \cdot \exp \left[-\left(\frac{\varepsilon}{F_{0}}\right)^{m}\right]
$$

In the model diagram of siltstone with different joint thickness (Figure 2), the upper and lower parts are both siltstone of the same type, and the joint of varying thickness is the coal layer in the middle. The stress for each part can be expressed by equations (9)-(11): 


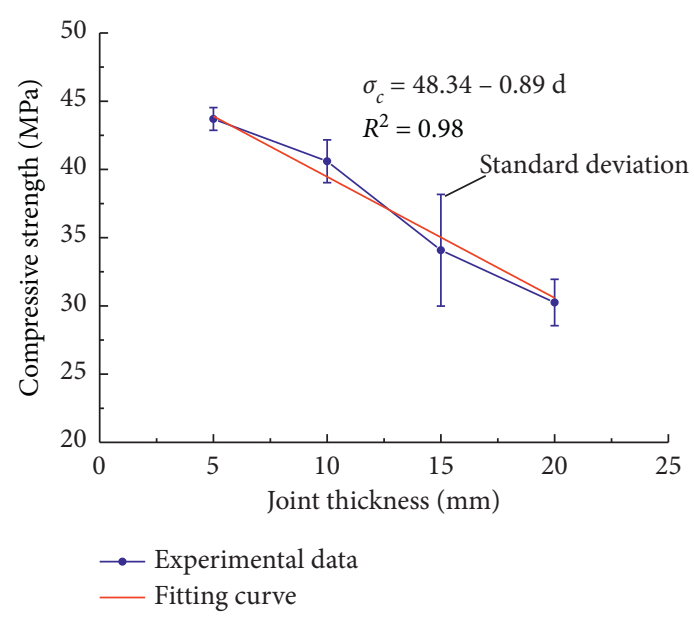

(a)

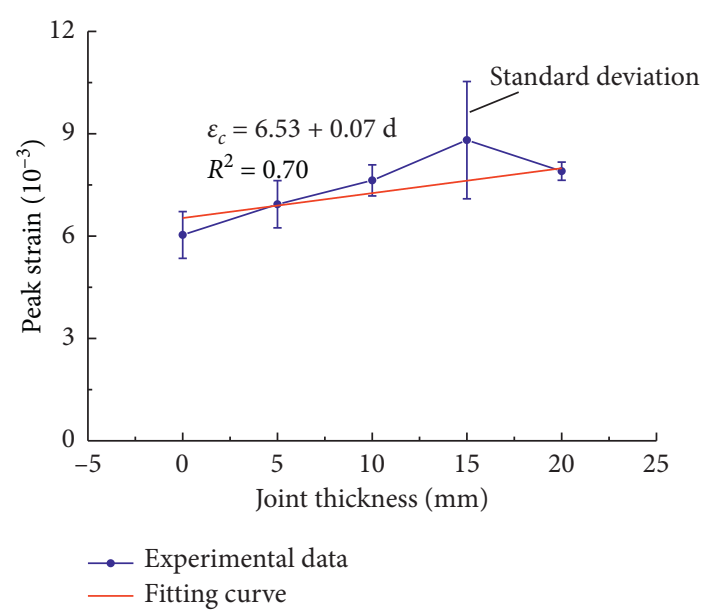

(b)

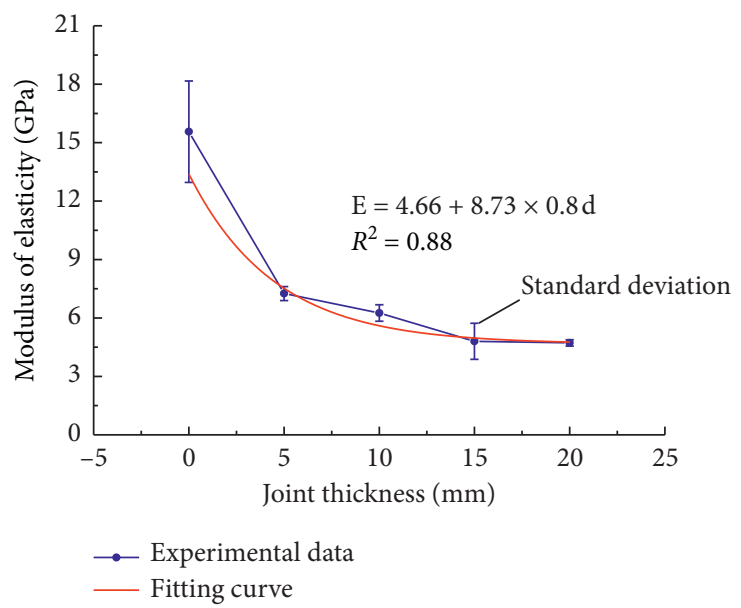

(c)

FIGURE 5: Relationship between the joint thickness and uniaxial compression mechanical parameters: (a) compressive strength, (b) peak strain, and (c) modulus of elasticity.

$$
\begin{aligned}
& f\left(\varepsilon_{1}\right)=E_{1} \cdot \varepsilon_{1} \cdot \exp \left[-\left(\frac{\varepsilon_{1}}{F_{01}}\right)^{m_{1}}\right], \\
& f\left(\varepsilon_{2}\right)=E_{2} \cdot \varepsilon_{2} \cdot \exp \left[-\left(\frac{\varepsilon_{2}}{F_{02}}\right)^{m_{2}}\right], \\
& f\left(\varepsilon_{3}\right)=E_{3} \cdot \varepsilon_{3} \cdot \exp \left[-\left(\frac{\varepsilon_{3}}{F_{02}}\right)^{m_{3}}\right] .
\end{aligned}
$$

The load and deformation for each part can be expressed by equations (12)-(14) (Lu et al. [27]):

$$
\begin{aligned}
& F_{1}=f\left(u_{1}\right)=\lambda_{1} \cdot u_{1} \cdot \exp \left[-\left(\frac{u_{1}}{F_{01}}\right)^{m_{1}}\right], \\
& F_{2}=f\left(u_{2}\right)=\lambda_{2} \cdot u_{2} \cdot \exp \left[-\left(\frac{u_{2}}{F_{02}}\right)^{m_{2}}\right],
\end{aligned}
$$

$$
F_{3}=f\left(u_{3}\right)=\lambda_{3} \cdot u_{3} \cdot \exp \left[-\left(\frac{u_{3}}{F_{02}}\right)^{m_{3}}\right] .
$$

The deformation rate is definite during the loading process of the jointed siltstone, and the deformation in unit time is thus definite. Since the total deformation and load are the sum of the parts, the following equations can be established:

$$
u_{1}+u_{2}+u_{3}=u
$$

$$
f\left(u_{1}\right)=f\left(u_{2}\right)=f\left(u_{3}\right)
$$

where $u_{1}$ is the deformation of the upper siltstone $(\mathrm{mm}), u_{2}$ is the deformation of the coal joint ( $\mathrm{mm}), u_{3}$ is the deformation of the lower siltstone (mm), and $u$ is the total deformation $(\mathrm{mm})$.

Equations (12)-(14) can be converted to the following when the increment of the load is taken as $\Delta F$ (Liu et al. [28]): 


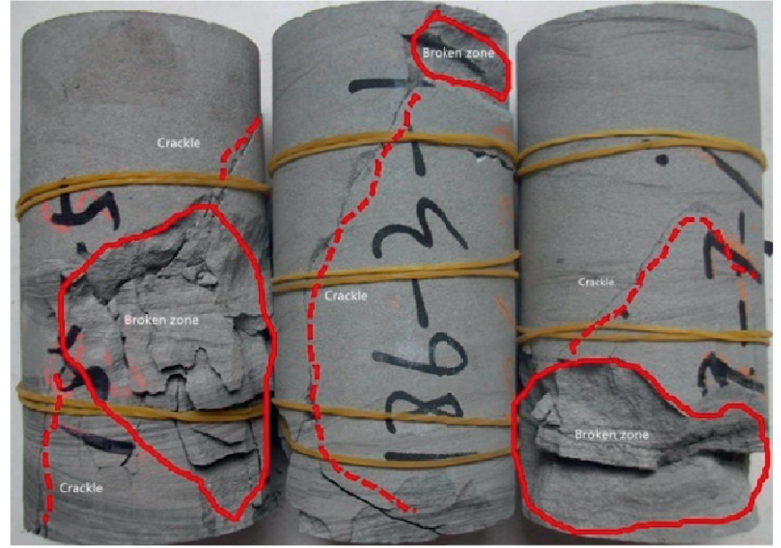

(a)

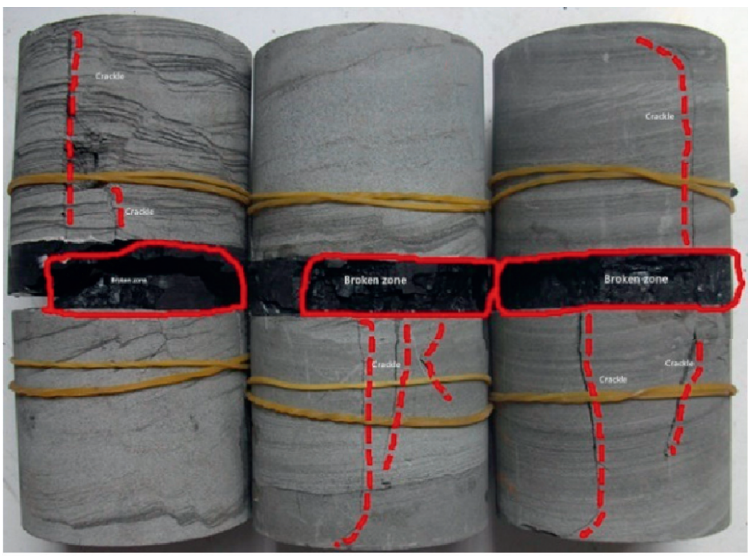

(c)

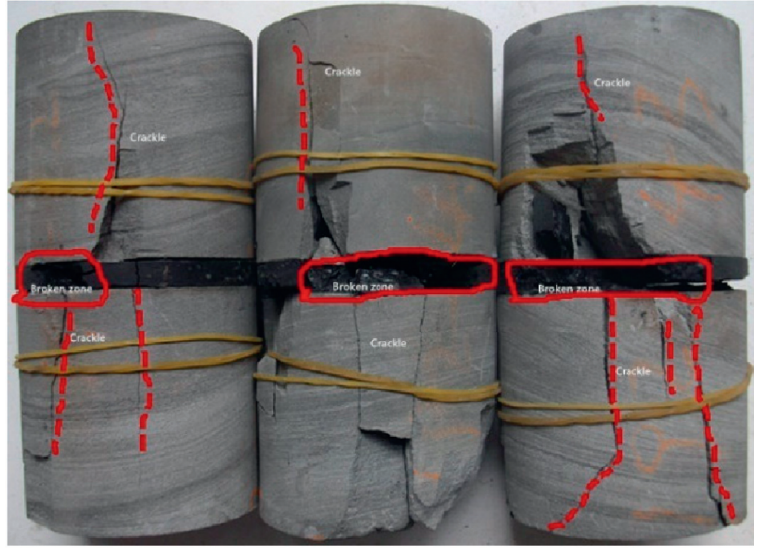

(b)

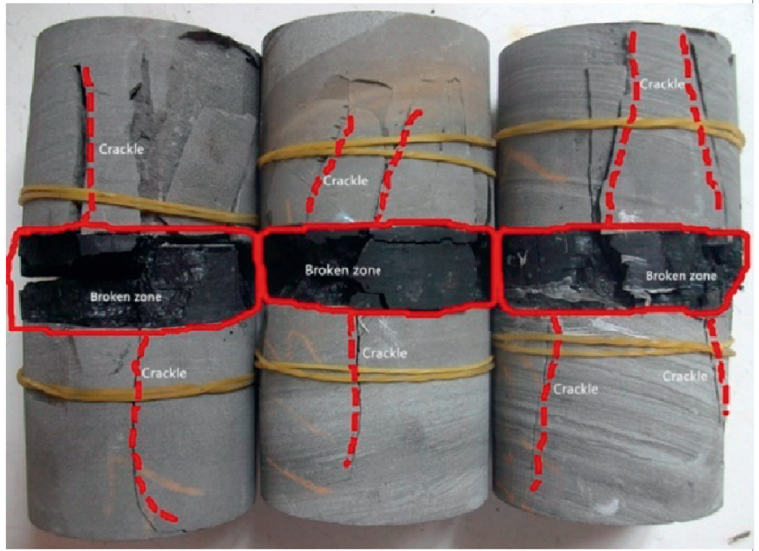

(d)

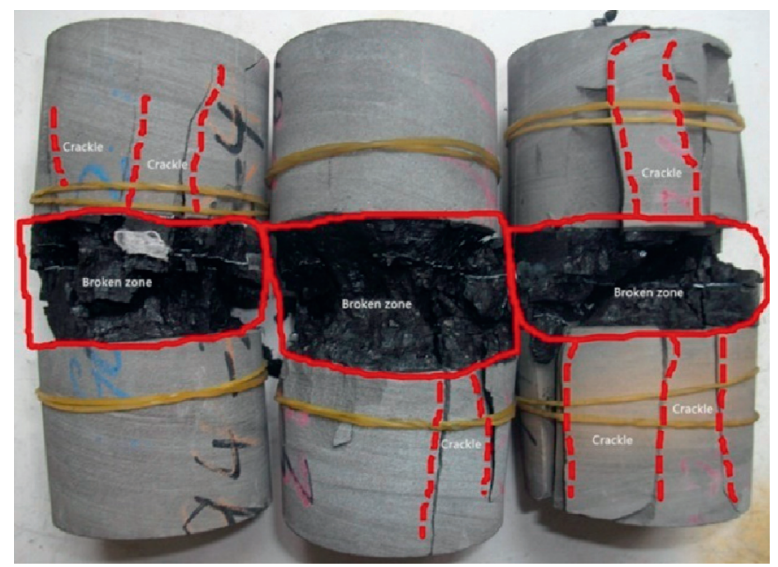

(e)

FIGURE 6: Failure forms of siltstone in the structural planes with different thickness under uniaxial compression. Specimens of (a) intact siltstone or jointed siltstone with (b) $5 \mathrm{~mm}$, (c) $10 \mathrm{~mm}$, (d) $15 \mathrm{~mm}$, and (e) $20 \mathrm{~mm}$ thick coal.

$$
\begin{aligned}
& \Delta F_{1}=f_{1}^{\prime}\left(u_{1}\right) \Delta u_{1}, \\
& \Delta F_{2}=f_{2}^{\prime}\left(u_{2}\right) \Delta u_{2}, \\
& \Delta F_{3}=f_{3}^{\prime}\left(u_{3}\right) \Delta u_{3} .
\end{aligned}
$$

The total deformation increment of the jointed siltstone can be expressed as follows:

$$
\Delta u=\Delta u_{1}+\Delta u_{2}+\Delta u_{3} .
$$

Because the upper and lower siltstone parts are the same, equation (20) can be simplified as

$$
\Delta u=2 \Delta u_{1}+\Delta u_{2}=\Delta u_{2}\left(\frac{2 \Delta u_{1}}{\Delta u_{2}}+1\right)=\Delta u_{1}\left(2+\frac{\Delta u_{2}}{\Delta u_{1}}\right) .
$$




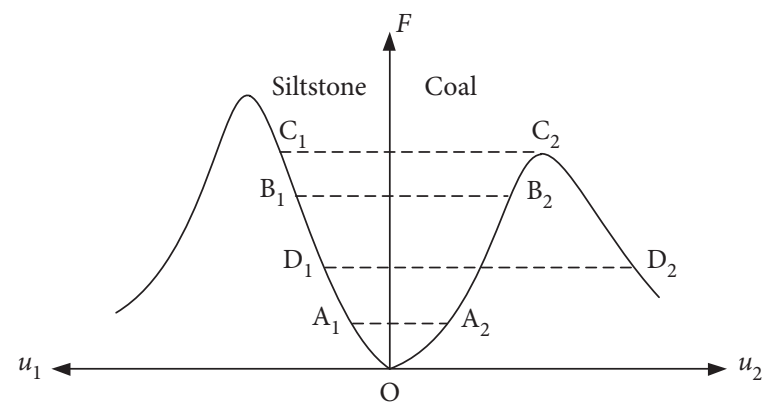

FIGURE 7: Load-displacement curve of coal specimen and siltstone.

Equations (22) and (23) can be obtained from equations

(17), (18), and (21):

$$
\begin{aligned}
& \frac{\Delta u_{2}}{\Delta u}=\frac{1}{\left(\left(2 \Delta u_{1} / \Delta u_{2}\right)+1\right)}=\frac{1}{\left(\left(2 \Delta F_{1} \cdot f_{2}^{\prime}\left(u_{2}\right) / \Delta F_{2} \cdot f_{1}^{\prime}\left(u_{1}\right)\right)+1\right)}=\frac{1}{\left(\left(2 f_{2}^{\prime}\left(u_{2}\right) / f_{1}^{\prime}\left(u_{1}\right)\right)+1\right)}, \\
& \frac{\Delta u_{1}}{\Delta u}=\frac{1}{\left(\left(\Delta u_{2} / \Delta u_{1}\right)+2\right)}=\frac{1}{\left(\left(\Delta F_{2} \cdot f_{1}^{\prime}\left(u_{1}\right) / \Delta F_{1} \cdot f_{2}^{\prime}\left(u_{2}\right)\right)+2\right)}=\frac{1}{\left(\left(f_{1}^{\prime}\left(u_{1}\right) / f_{2}^{\prime}\left(u_{2}\right)\right)+2\right)} .
\end{aligned}
$$

Figure 7 plots the axial load deformation of the jointed siltstone.

Figure 7 demonstrates the changes in the loading and deformation process of the joint siltstone, which can be further divided into the following stages:

The first stage (OA): both siltstone and coal are subjected to axial load, and the primary pores and cracks are gradually compressed.

The second stage $(\mathrm{AB})$ : both siltstone and coal are subjected to axial load, and accumulating elastic energy. Some microfractures are generated. $f_{1}^{\prime}\left(u_{1}\right)$ and $f_{2}^{\prime}\left(u_{2}\right)$ are constant thus far.

The third stage (BC): coal begins plastic deformation under the axial load. Here $f_{2}^{\prime}\left(u_{2}\right)$ gradually decreases, eventually to 0 (point $C_{2}$ on the right half of the curve in Figure 7), but $f_{1}^{\prime}\left(u_{1}\right)$ remains constant. According to equation (23), at $C_{2}, \quad\left(f_{2}^{\prime}\left(u_{2}\right) / f_{1}^{\prime}\left(u_{1}\right)\right)=0$ and $\left(\Delta u_{1} / \Delta u\right)=1$.

The fourth stage (CD): the bearing capacity of coal gradually declines. The siltstone begins to unload and release elastic energy, which damages the coal even further. Here, $f_{1}^{\prime}\left(u_{1}\right)$ is constant and $f_{2}^{\prime}\left(u_{2}\right)$ increases gradually, and $\left(\Delta u_{2} / \Delta u\right) \longrightarrow \infty$ when $f_{1}^{\prime}\left(u_{1}\right)=-2 f_{2}^{\prime}\left(u_{2}\right)$. Instability and failure of the jointed siltstone occurs as a result.

According to the above analysis, point $\mathrm{C}_{2}$ (Figure 7) becomes closer to the peak point of siltstone when the joint thickness is higher, and the siltstone can then more easily enter plastic failure. Therefore, in the case of uniaxial compression, plastic failure will run through the coal joint in the middle, and the damage to the siltstone will be greater when the joint thickness is low. But as the coal joint thickens, point $\mathrm{C}_{2}$ of coal becomes farther away from the peak load of siltstone, and the load of coal sample failure does not exceed the peak load of siltstone elastic stage. Therefore, there will be no obvious damage to the siltstone parts during uniaxial compression, and the damage of coal samples becomes more serious.

\section{Conclusions}

Uniaxial compression test was carried out for jointed siltstone to analyze how the joint thickness affected the peak compressive strength, the uniaxial strain, and the elastic modulus. The failure mechanism was also discussed. Joint thickness had an obvious influence on the stress-strain curve of the jointed siltstone. With rising joint thickness, the initial compaction intensified, the slope of the straight line in the linear elastic stage decreased gradually, and the appearance of the curve drop in the postpeak stage became more obvious. Joint thickness also had a negative correlation with the peak compressive strength and the elastic modulus but a positive correlation with the peak strain.

In addition, joint thickness had an obvious influence on the failure mode and damage degree. With rising joint thickness, the damage weakened in the siltstone part but intensified in the coal part. The failure process of the jointed siltstone can be divided into four stages. In the first stage, both $f_{1}^{\prime}\left(u_{1}\right)$ and $f_{2}^{\prime}\left(u_{2}\right)$ are positive and increase with rising stress. In the second stage, both $f_{1}^{\prime}\left(u_{1}\right)$ and $f_{2}^{\prime}\left(u_{2}\right)$ remain constant. In the third stage, $f_{1}^{\prime}\left(u_{1}\right)$ is constant whereas $f_{2}^{\prime}\left(u_{2}\right)$ gradually decreases with rising stress, and at the peak point $C_{2}, f_{2}^{\prime}\left(u_{2}\right) / f_{1}^{\prime}\left(u_{1}\right)=0$ and $\left(\Delta u_{1} / \Delta u\right)=1$. In the fourth stage, $f_{1}^{\prime}\left(u_{1}\right)$ is constant and $f_{2}^{\prime}\left(u_{2}\right)$ gradually increases but is now negative. When $f_{1}^{\prime}\left(u_{1}\right)=-2 f_{2}^{\prime}\left(u_{2}\right),\left(\Delta u_{2} / \Delta u\right) \longrightarrow \infty$, the jointed siltstone becomes unstable and fails. 


\section{Data Availability}

The data used to support the findings of this study are available from the corresponding author upon request.

\section{Conflicts of Interest}

The authors declare that there are no conflicts of interest regarding the publication of this paper.

\section{Acknowledgments}

This research was funded by the Chinese Natural Science Committee under grant no. U1261207, a Key Discipline of Mining Engineering in Guizhou Province (ZDXK [2016] 13), Research Initiation Fund for High-Level Talents (YKHZG2018011), and Natural Science Foundation of Guizhou Education Department (Qianjiaohe KY Zi [2019] 166).

\section{References}

[1] F. Du and S. S. Peng, "Change rule of physical and mechanical property of rock mass in Shendong mine," Journal of Mining and Safety Engineering, vol. 36, no. 5, pp. 1009-1015, 2019.

[2] H. M. Li, Y. F. Liang, J. F. Chen, H. G. Li, and X. Q. Chen, "Relationship between pore structural characteristics and physical-mechanical properties of sandstone in Shendong mining area," Journal of Henan Polytechnic University (Natural Science), vol. 37, no. 4, pp. 9-16, 2018.

[3] Y. X. Zhao, B. Liu, Z. L. Yang, G. J. Song, and D. H. Yang, "Tensile strength and fracture toughness of sedimentary rocks at different buried depths in Shendong coal field," Journal of China Coal Society, vol. 44, no. 6, pp. 1732-1741, 2019.

[4] J. F. Ma and X. Q. Li, "Study on models of aquifer failure caused by coal mining in Shendong mining area," Coal Science and Technology, vol. 47, no. 3, pp. 207-213, 2019.

[5] X. F. Chen, X. X. Zhao, H. B. Wang, L. Ma, and C. B. Wang, "Model tests and application research on propagation laws of blasting stress wave in jointed and filled rock mass," Journal of Safety Science and Technology, vol. 14, no. 12, pp. 130-134, 2018.

[6] L. Lian, S. B. Zhang, Y. Wang, G. Wang, and H. Wang, "Macro-microscopic study on shear failure behavior of joints under different filling thicknesses," Journal of Guangxi University (Natural Science Edition), vol. 44, no. 3, pp. 756-764, 2019.

[7] Z. F. Chen, J. Xiang, W. C. Fan, and N. Fu, "Influence of different filling degree on failure mechanism of rock joint," China Science Paper, vol. 14, no. 6, pp. 614-619, 2019.

[8] G. K. Zhang, H. B. Li, X. Xia, N. N. Li, and S. B. Chai, "Influence of joint features on mechanical properties of rock mass," Journal of Central South University, vol. 47, no. 12, pp. 4198-4205, 2016.

[9] Y. Li, W. Liu, C. Yang, and J. J. K. Daemen, "Experimental investigation of mechanical behavior of bedded rock salt containing inclined interlayer," International Journal of Rock Mechanics and Mining Sciences, vol. 69, pp. 39-49, 2014.

[10] Y. Q. Song, M. Li, J. Liu, T. Zhou, and C. A. Sun, "Experimental test on marble containing natural weak interlayer of different angles," Journal of China University of Mining \& Technology, vol. 44, no. 4, pp. 623-629, 2015.
[11] Z. Q. Ke, H. L. Wang, W. Y. Xu, Z. N. Lin, and H. Ji, "Experimental study of mechanical behaviour of artificial columnar jointed rock mass containing transverse joints," Rock and Soil Mechanics, vol. 40, no. 2, pp. 660-667, 2019.

[12] P. L. P. Wasantha, S. M. Asce, P. G. Ranjith, F. Asce, and D. R. Viete, "Specimen slenderness and the influence of joint orientation on the uniaxial compressive strength of singly jointed rock," Journal of Materials in Civil Engineering, vol. 26, no. 6, pp. 1-4, 2014.

[13] M. Wang, Z. M. Zhu, and J. Xie, "An experimental study on deformation fractures of fissured rock around tunnels in true triaxial unloads," Advances in Materials Science and Engineering, vol. 2015, Article ID 982842, 2015.

[14] X. R. Liu, Z. Y. Deng, Y. Q. Liu, Y. M. Lu, S. L. Liu, and Y. F. Han, "Macmscopic and microscopic analysis of particle now in pre-peak cyclic direct shear test of rock joint," Journal of China Coal Society, vol. 44, no. 7, pp. 2103-2115, 2019.

[15] C. Q. Su and Q. H. Wu, "Study of mechanical property of limestone specimens with natural continuous weak plane," Chinese Journal of Rock Mechanics and Engineering, vol. 30, no. S2, pp. 3944-3952, 2011.

[16] D. M. Guo, J. P. Zuo, Y. Zhang, and R. S. Yang, "Research on strength and failure mechanism of deep coal-rock combination bodies of different inclined angles," Rock and Soil Mechanics, vol. 32, no. 5, pp. 1333-1339, 2011.

[17] M. R. Vergara, M. Van Sint Jan, and L. Lorig, "Numerical model for the study of the strength and failure modes of rock containing non-persistent joints," Rock Mechanics and Rock Engineering, vol. 49, no. 4, pp. 1211-1226, 2016.

[18] M. Bahaaddini, P. Hagan, R. Mitra, and B. K. Hebblewhite, "Numerical study of the mechanical behavior of nonpersistent jointed rock masses," International Journal of Geomechanics, vol. 16, no. 1, Article ID 04015035, 2016.

[19] Q. Yu, S. Yang, P. G. Ranjith, W. Zhu, and T. Yang, "Numerical modeling of jointed rock under compressive loading using X-ray computerized tomography," Rock Mechanics and Rock Engineering, vol. 49, no. 3, pp. 877-891, 2016.

[20] Y. Yang, R. S. Yang, and J. G. Wang, "Simulation material experiment on dynamic mechanical properties of jointed rock affected by joint thickness," Journal of China University of Mining \& Technology, vol. 45, no. 2, pp. 211-216, 2016.

[21] H. Z. Yu, H. N. Ruan, and W. J. Chu, "Particle flow code modeling of shear behavior of rock joints," Chinese Journal of Rock Mechanics and Engineering, vol. 32, no. 7, pp. 1482-1490, 2013.

[22] P. T. Wang, T. H. Yang, Q. L. Yu, and W. H. Shi, "Uniaxial compression test and numerical simulation of stratified biotite granulite," Journal of Northeastern University (Natural Science), vol. 36, no. 11, pp. 1633-1637, 2015.

[23] J. Lemaitre, "Evaluation of dissipation and damage in metals submitted to dynamic loading," in Proceedings of the ICM1, Kyoto, Japan, September 1971.

[24] X. Z. Wu, J. W. Liu, X. X. Liu, K. Zhao, and Y. B. Zhang, "Study on the coupled relationship between AE accumulativering-down count and damage constitutive model of rock," Journal of Mining \& Safety Engineering, vol. 32, no. 1, pp. 28-34, 2015.

[25] Q. Sun, W. Q. Zhang, L. Xue, H. T. Qian, and S. Y. Zhu, "Acoustic emission characteristics in quasi-quiet stage of damage and fracture of sandstone," Journal of Mining \& Safety Engineering, vol. 30, no. 2, pp. 237-242, 2013.

[26] D. Q. Liu, Study on Rock Damage Constitutive Model and Chaos Characteristics in the Process of Deformation and 
Failure, China University of Mining and Technology, Beijing, China, 2014.

[27] C. P. Lu, "Intensity weakening theory for rockburst of compound coal-rock and its application," Xuzhou: Chinese Journal of Geotechnical Engineering, vol. 30, no. 6, 2008.

[28] J. X. Liu, C. A. Tang, W. C. Zhu, and T. H. Yang, "Rock-coal model for studying the rockburst," Chinese Journal of Geotechnical Engineering (Beijing), vol. 26, no. 2, pp. 276-280, 2004. 